Western University Scholarship@Western

1981

\title{
Monopoly versus Competition under Uncertainty
}

Elie Appelbaum

Chin Lim

Follow this and additional works at: https://ir.lib.uwo.ca/economicsresrpt

Part of the Economics Commons

Citation of this paper:

Appelbaum, Elie, Chin Lim. "Monopoly versus Competition under Uncertainty." Department of Economics Research Reports, 8103. London, ON: Department of Economics, University of Western Ontario (1981). 
ISSN: $0318-725 \mathrm{X}$

ISBN: $\quad 0-7714-0251-1$

RESEARCH REPORT 8103

MONOPOLY VERSUS COMPETITION UNDER

UNCERTAINTY

by

Elie Appelbaum and Chin Lim

February 1981 


\section{Introduction}

$$
\text { - ฉ ก } 1981
$$

A very well-known result, one which is incorporated into every Intermediate microeconomics text is that, given similar demand and cost conditions, a competitive industry will produce a higher output (at a lower price) than a monopolist. Moreover, the existence of monopoly involves a deviation from marginal cost pricing and, therefore, leads to a welfare $108 s$ to society.

This result is, of course, not surprising since the point of reference is the "first best" world of competition with no imperfections.

In this paper, we compare monopoly and competition considering that the world is characterized by uncertainty and imperfect information and is, thus, imperfect. Given that such an imperfection exists and cannot be removed, we demonstrate that the traditional results may be reversed.

In particular, we show that given an exogenous demand uncertainty ${ }^{1}$ which cannot be removed (diversified away), there exists several effects, all working to reduce the costs of uncertainty of the monopolist relative to those of the competitive industry. Thus even when production costs are similar, the "full costs"--production costs and costs of uncertainty--of a monopolist are generally lower than those of a competitive industry.

From a welfare point of view, it follows that, with uncertainty, monopoly is less undesirable than without uncertainty. Furthermore, within the environment of uncertainty, monopoly may turn out to be even more desirable than competition since competition under these conditions may in fact be further away from the unattainable first best position.

Our results raise questions as to the validity of the so-called Galbraith-Caves hypothesis ${ }^{2}$ that monopolists take out some of their rents in the form of risk avoidance, or alternatively, that risk avoidance increases with market power. A corollary of our analysis is that the Galbraith-Caves hypothesis 
Is in general not true ${ }^{3}$ and it is in fact possible for a monopolist to exhlbit less risk avoidance than a competitive firm.

Finally, we show that our results have some interesting implications with respect to the measurement of the degree of monopoly power.

In Section II we present the competitive industry model with demand uncertainty. In Section III we consider the monopoly's problem. Section IV provides a comparison of the two models and in Section $V$ we consider the implications of our results.

II. The Competitive Industry

Consider a competitive industry facing a random market demand function

$$
\mathrm{p}=\mathrm{p}(\mathrm{q}, \epsilon), \quad \frac{\partial \mathrm{p}}{\partial \mathrm{q}}<0, \quad \frac{\partial \mathrm{p}}{\partial \epsilon}>0
$$

where $p$ is price; is a random variable with probability density, $d \Psi(e)$;

$$
q=\sum_{i=1}^{N} q_{i}
$$

is the aggregate industry output and $q_{i}(i=1, \ldots, N)$ is the output of the $i^{\text {th }}$ firm in the industry. We assume all firms to be identical in that they have an identical increasing concave utility function, $U(\cdot)$, a cost function, $C\left({ }^{\cdot}\right)$, and a profit function $\pi\left(q_{i}\right)=p(q, \varepsilon) \cdot q_{i}-c\left(q_{i}\right)$. These assumptions imply $\mathrm{q}=\mathrm{Nq}_{\mathbf{i}} \cdot$

As a simplification, we assume that the probability density function, $d \Psi(\epsilon)$, is sufficiently concentrated and compact so that we can approximate the expected utility function as ${ }^{4}$

$$
\mathrm{E}[\mathrm{U}(\pi)]=\mathrm{U}\left(\bar{\pi}-\frac{1}{2} \mathrm{R}(\bar{\pi}) \mathrm{q}_{1}^{2} \sigma^{2}\right)
$$

where $\bar{\pi} \equiv E[\pi]$ is the firm's expected profit (E is an expectations operator); $R(\cdot)=\frac{-U^{\prime \prime}(\cdot)}{U^{\prime}(\cdot)}$ is the Arrow-Pratt measure of absolute risk aversion which following Arrow (1965) is assumed to be decreasing in its argument so that $R^{\prime}()<0 ; \sigma^{2}$ is the variance of the price level; and $\frac{1}{2} R(\bar{\pi}) q_{i}^{2} \sigma^{2}$ is the risk premium. As can be seen from (1), the absence of any further restrictions implies the variance of $p$ is in general not constant but some function of $q$. 
We, therefore, write $\sigma^{2}=\sigma^{2}\left(q ; s^{2}\right)$ with $\frac{\partial \sigma^{2}}{\partial s^{2}}>0$, where $s^{2}$ is the true variance of the distribution of $\varepsilon_{\text {. }}$

In the short-run equilibrium, the number of firms, say $N$, is given, and the equilibrium firm size, $q_{i}$, is derived simply by maximizing expected utility (3). In the long run, however, where there is free entry, the number of firms and the size of each firm are endogenously determined as a solution to the competitive industry's long-run equilibrium conditions. Firstly, free entry leads to zero expected utility, $E[U(\pi)]=0$, which after using (3) and the assumption that $U(0)=0$ implies

$$
\text { (4) } \quad \Delta^{0} \equiv \bar{\pi}-\frac{1}{2} R(\bar{\pi}) q_{i}^{2} \sigma^{2}=0 \quad \text { all i. }
$$

This simply states that in the long-run equilibrium, the expected profit of each firm must be equal to the risk premium. Secondly, in equilibrium the output, $q_{1}$, of each firm is optimally chosen to maximize expected utility (3), which yields, after some manipulations, the first-order necessary conditions

$$
\Delta \equiv E(p)-C^{\prime}\left(q_{i}\right)-\frac{R(\bar{\pi}) q_{i} \sigma^{2}}{1-\frac{1}{2} R^{\prime}(\bar{\pi}) q_{i}^{2} \sigma^{2}}=0 \quad \text { all } 1
$$

Note that in this derivation, it is assumed $\partial q / \partial q_{i}=0$ so that the price distribution (here represented by $E[P]$ and $\sigma^{2}$ ) is unaffected by a competitive firm's choice of $q_{i}$.

If we define the firm's marginal risk premium as

$$
\alpha\left(q_{i}, q\right)=\frac{R(\bar{\pi}) q_{i} \sigma^{2}}{1-\frac{1}{2} R^{\prime}(\bar{\pi}) q_{i}^{2} \sigma^{2}}
$$

then condition (5) can be simplified as

$$
E(p)=c^{\prime}\left(q_{i}\right)+\alpha\left(q_{i}, q\right)
$$

which says that the competitive firm maximizes its expected utility of profits by equating the expected price with what can be called "full" or "effective" marginal costs which is the sum of the marginal costs of production, $c^{\prime}\left(q_{i}\right)$, 
and the marginal cost of uncertainty, given by the marginal risk premium, $\alpha\left(q_{i}, q\right)$

The second-order condition requires that

$$
\frac{\partial \Delta}{\partial q_{1}}<0 \quad \text { all i. }
$$

The system of equations (1), (4) and (5) determines the number of firms in the industry, the size of each firm, total output and price. Let this solution be given by $N, q_{i}, q_{c}=N q_{i}$ and $p\left(q_{c}, \epsilon\right)$, respectively. Corresponding to the equilibrium values of the endogenous variables we get the competitive firm's marginal risk premium

$$
\alpha_{c}\left(q_{c}\right) \equiv \alpha\left(q_{i}, q_{c}\right)=\frac{R\left(\bar{\pi}_{c}\right) q_{i}^{2} \sigma_{c}^{2}}{1-\frac{1}{2} R\left(\bar{\pi}_{c}\right) q_{i}^{2} \sigma_{c}^{2}}
$$

where $\sigma_{c}^{2} \equiv \sigma^{2}\left(q_{c} ; s^{2}\right)$ is the variance of the equilibrium price facing the competitive industry and $\bar{\pi}_{c} \equiv E\left[p\left(q_{c}, \epsilon\right) q_{i}-c\left(q_{i}\right)\right]$ is the competitive firm's expected profits.

\section{Monopoly}

In order that the comparison between monopoly and competitive equilibrium be meaningful, it is necessary that the monopolist's cost function be appropriately defined. In the certainty model, the prediction that monopoly output is always less than that of competitive equilibrium stems from the crucial assumption that the marginal cost curve of the monopolist is identically the horizontal summation of the marginal cost curves of the competitive firms in equilibrium (or the aggregate supply of the cometitive industry). In what follows, a similar definition is used, thus allowing us to concentrate on the effects of uncertainty, rather than other effects such as the economies of scale in production. 
Recall that in the preceding section an individual firm's cost function was defined as $c\left(q_{1}\right)$ for all $i$. Since all firms are assumed identical, so that the aggregate output $q_{c}=N_{i}$, the total cost of the competitive industry producing the aggregate output $q_{c}$ (and with each firm producing $q_{i}$ ) can be written as

$$
C_{c}\left(q_{c}\right)=\operatorname{NC}\left(q_{i}\right)
$$

Differentiating the above with respect to $q_{i}$ yields

$$
c_{c}^{\prime}\left(q_{c}\right)=c^{\prime}\left(q_{i}\right)
$$

where $c^{\prime}\left(q_{i}\right)$ is the marginal cost of an individual firm whereas $c_{c}^{\prime}\left(q_{c}\right)$ is the "horizontal summation" of the firms' marginal costs. Note also that (11) Implies $c_{c}^{\prime \prime}\left(q_{c}\right)=\frac{1}{N} c^{\prime \prime}\left(q_{1}\right)$ which says that the slope of the industry's marginal cost (or the "horizontal summation" of individual marginal costs) is $1 / N$ of the slope of each individual firm's marginal cost schedule. Using $C_{c}(\cdot)$ as the appropriate monopoly cost function, we shall now proceed to analyze the monopoly problem.

Consider a monopolist which has the same utility function $U(\cdot)$; which faces the same demand curve given by $(1)$; and whose cost function $c_{c}(\cdot)$ is defined in (10). Let $q_{m}$ be the monopoly equilibrium output, then 1 th mst satisfy the first-order condition

$$
\Delta^{m} \equiv\left\{E\left[p\left(q_{m}, e\right)\right]+E\left[\delta\left(q_{m}, \varepsilon\right)\right]\right\}-\left\{c_{c}^{\prime}\left(q_{m}\right)+\alpha_{m}\left(q_{m}\right)\right\}=0
$$

where

$$
\delta \equiv \frac{\partial p}{\partial q_{m}} q_{m}<0
$$

and

$$
\alpha_{m}\left(q_{m}\right) \equiv \frac{R\left(\bar{\pi}_{m}\right) q_{m}\left[\sigma_{m}^{2}+\frac{q_{m}}{2} \frac{\partial \sigma_{m}^{2}}{\partial q_{m}}\right]}{1-\frac{1}{2} R^{\prime}\left(\bar{\pi}_{m}\right) q_{m}^{2} \sigma_{m}^{2}}
$$

is the monopolist's marginal risk premium; $\sigma_{m}^{2} \equiv \sigma^{2}\left(q_{m} ; s^{2}\right)$ and $\frac{\partial \sigma_{m}^{2}}{\partial q_{m}}$ are the 
variance and the marginal variance of price faced by the monopolist; and $\bar{\pi}_{\mathrm{m}} \equiv \mathrm{E}\left[\mathrm{p}\left(\mathrm{q}_{\mathrm{m}}, f_{0}\right) \mathrm{q}_{\mathrm{m}}-\mathrm{C}_{\mathrm{c}}\left(\mathrm{q}_{\mathrm{m}}\right)\right]$ is the monopolist's expected profit in equilibrium. Furthermore, the second order condition requires

$$
\frac{\partial A^{m}}{\partial q_{m}}<0
$$

Condition (12) states that the monopoly optimum is one that equates the expected marginal revenue $\{E[P]+E[\delta]\}$ with the "effective" marginal costs which consist of the marginal production cost, $c_{c}^{\prime}$, plus the marginal cost of uncertainty or marginal risk premium given by $\alpha_{\mathrm{m}}$. Notice, however, that $\alpha_{\mathrm{m}}$, in contrast with $\alpha_{c}$, contains an additional term $\partial \sigma_{\mathrm{m}}^{2} / \partial \mathrm{q}_{\mathrm{m}}$. This term is zero for the case of the competitive firm since the output of the competitive firm, by definition, cannot affect the price or the variance of the industry price. In the case of a monopolist, however, $\partial \sigma_{m}^{2} / \partial q_{m}$ is in general not zero and could take on a positive or negative value depending on the stochastic nature of the demand function.

\section{Monopoly Versus Competition}

The comparison between monopoly and competition is now conveniently facilitated by rewriting the monopoly equilibrium condition (12) as

$$
E\left[p\left(q_{m}, \theta\right)\right]=-E\left[\delta\left(q_{m}, \theta\right)\right]+C_{c}^{\prime}\left(q_{m}\right)+\alpha_{m}\left(q_{m}\right)
$$

and the competitive firm's equilibrium condition (5) as (after using (6), (9) and (11)):

$$
E\left[p\left(q_{c}, e\right)\right]=c_{c}^{\prime}\left(q_{c}\right)+\alpha_{c}\left(q_{c}\right)
$$

The question that confronts us is whether or not it is possible for the monopoly equilibrium output $q_{m}$ to exceed the competitive equilibrium output $q_{c}$. In addressing this question, observe that the monopoly equilibrium condition (16) holds only for equilibrium output $q_{m}$. For any other output $q_{m}^{0} \neq q_{m}$ (where $q_{m}^{0}$ is any arbitrary value in the neighbourhood of $q_{m}$ ), the second-order condition (15) implies. 


$$
E\left[p\left(q_{m}^{0}, \epsilon\right)\right] \gtrless-E\left[\delta\left(q_{m}^{0}, \epsilon\right)\right]+c_{c}^{\prime}\left(q_{m}^{0}\right)+\alpha_{m}\left(q_{m}^{0}\right) \text { iff } q_{m}^{0} \lessgtr q_{m}
$$

Now if we let $q_{c}=q_{m}^{0}$, then

$$
E\left[p\left(q_{c}, \theta\right)\right] \gtrless-E\left[\delta\left(q_{c}, a\right)\right]+c_{c}^{\prime}\left(q_{c}\right)+\alpha_{m}\left(q_{c}\right) \text { iff } q_{c} \leqslant q_{m}
$$

and using (17),

$$
\alpha_{c}\left(q_{c}\right) \gtrless-E\left[\delta\left(q_{c}, \theta\right)\right]+\alpha_{m}\left(q_{c}\right) \text { iff } q_{c} \lessgtr q_{m}
$$

In what follows, our motive is to present sufficient conditions such that

$$
\alpha_{c}\left(q_{c}\right)-\alpha_{m}\left(q_{c}\right)+E\left[\delta\left(q_{c}, \varepsilon\right)\right]>0 \Rightarrow q_{c}<q_{m}
$$

Since $E[\delta]<0$, it is obvious that condition (18) can never be

satisfied when there is no uncertainty or when there is risk neutrality. The reason is in both of these cases, $\alpha_{c}=\alpha_{m}=0$ so that a monopolist, by the standard prediction, will always produce a lower output. However, in the presence of uncertainty and risk aversion, it is possible that a monopolist may produce a higher output level compared to that of competitive equilibrium. To demonstrate this, i.e., condition (18), what is required is that the marginal risk premium (or avoidance) or the monopolist $\left(\alpha_{m}\right)$ to be oufficiently smaller than that $\left(\alpha_{c}\right)$ of a competitive firm--a requirement which obviously contradicts the Galbraith-Caves hypothesis that the monopolist should exhibit a greater risk avoidance. In what follows, it will be shown how several factors may contribute toward assuring $\left(\alpha_{c}-\alpha_{m}\right)>>0$; thus making it possible that monopoly output may in fact exceed that of competitive equilibrium.

To begin with, observe that using the definitions of $\alpha_{c}$ and $\alpha_{m}$ in (9) and (14) respectively, the term 


$$
\alpha_{c}\left(q_{c}\right)-\alpha_{m}\left(q_{c}\right)=\frac{R\left(\bar{\pi}_{c}\left(q_{i}\right)\right) q_{i}}{1-\frac{1}{2} R^{\prime}\left(\pi_{c}\left(q_{i}\right)\right) q_{i}^{2} \sigma_{c}^{2}} \sigma_{c c}^{2}-\frac{R\left(\bar{\pi}_{m}\left(q_{c}\right)\right) q_{c}}{1-\frac{1}{2} R^{\prime}\left(\bar{\pi}_{m}\left(q_{c}\right)\right) q_{c}^{2} \sigma_{c m}^{2}}\left\{\sigma_{c m}^{2}+\frac{q_{c}}{2} \frac{\partial \sigma_{c m}^{2}}{\partial q_{c}}\right\}
$$

where we now introduce a new definition:

$$
\sigma_{c c}^{2} \equiv \sigma^{2}\left(q_{c}, s_{c}^{2}\right) \text { and } \sigma_{c m}^{2}=\sigma^{2}\left(q_{c}, s_{m}^{2}\right) \text {. }
$$

The reason for this is the true variance of $\varepsilon$ is in general unknown and needs to be estimated. As will be revealed shortly, the estimated variance $s_{\mathrm{m}}^{2}$ of the monopolist will in general differ from the competitive firm's estimated variance $s_{c}^{2}$. Before we evaluate expression (19), it is convenient to consider a few further simplifications. Firstly,

$$
\begin{aligned}
\bar{\pi}_{m}\left(q_{c}\right) & =E\left[p\left(q_{c}, \epsilon\right)\right] q_{c}-c_{c}\left(q_{c}\right) \\
& =N\left\{E\left[p\left(q_{c}, \theta\right) \cdot q_{i}-c\left(q_{1}\right)\right\}\right. \\
& =N \bar{\pi}_{c}\left(q_{i}\right)
\end{aligned}
$$

i.e., the expected profit of a monopolist at the output $q_{c}$ is $N$ times that of a competitive firm. Thus, because of the decreasing absolute risk aversion assumption,

$$
R\left(\bar{\pi}_{m}\left(q_{c}\right)\right)=\theta R\left(\bar{\pi}_{c}\left(q_{i}\right)\right) \text { where } 0<\theta \equiv \frac{R\left(N \bar{\pi}_{c}\left(q_{i}\right)\right)}{R\left(\pi_{c}\left(q_{i}\right)\right)}<1
$$

i.e., the absolute risk aversion factor of the monopolist is a fraction of that of a competitive firm. Secondly, defining

$$
\eta_{c} \equiv-R^{\prime}\left(\bar{\pi}_{c}\right) \bar{\pi}_{c} / R\left(\bar{\pi}_{c}\right)>0
$$

to be the (absolute) value of the elasticity of absolute risk aversion of the competitive firm, and recalling the competitive equilibrium condition (4), it follows that

$$
\eta_{c}=-\frac{1}{2} R^{\prime}\left(\bar{\pi}_{c}\right) q_{i}^{2} \sigma_{c}^{2}
$$

Thirdly, we assume

$$
\mathbf{R}^{\prime}\left(\bar{\pi}_{\mathbf{c}}\right)=\mathbf{R}^{\prime}\left(\bar{\pi}_{\mathbf{m}}\right)=\text { constant }
$$


which implies $R^{\prime \prime}=0$. This assumption is not at all restrictive since $R^{\prime \prime}$ involves the fourth derivative of the utility function on which neither economic theory nor intuition has much to say. 5

Substituting (20), (21) and (22) into (19), and after some manipulations, we have

$$
\begin{aligned}
& \alpha_{c}\left(q_{c}\right)-\alpha_{m}\left(q_{c}\right)=\lambda\left[\sigma_{c m}^{2}\left\{\left(N \eta_{c}-1\right)(N-1)+\left(1+\eta_{c}\right)(1-\theta) N\right\}\right. \\
&\left.+\left\{\sigma_{c c}^{2}-\sigma_{c m}^{2}\right\}-\left(1+\eta_{c}\right) \in N\left\{\frac{q_{c}}{2} \frac{\partial \sigma_{c m}^{2}}{\partial q_{c}}\right\}\right]
\end{aligned}
$$

where $\lambda \equiv R\left(\bar{\pi}_{c}\right) q_{i} /\left(1+\eta_{c}\right)\left(1+\eta_{c} N^{2} \sigma_{c m}^{2} / \sigma_{c c}^{2}\right)>0$. In observing (23), it is readily recognized that there are at least three effects, represented by the three terms within the parenthesis [ ], which work toward assuring $\alpha_{c}-\alpha_{\mathrm{m}}>>0$

The first effect is a direct result of decreasing absolute risk aversion or the economies of scale in the monopolist's risk avoidance which is represented by the term $\sigma_{c m}^{2}\left\{\left(N \eta_{c}-1\right)(N-1)+\left(1+\eta_{c}\right)(1-\theta) N\right\}$ in (23). This term is in general positive for the following reasons. First $\left(1+\eta_{c}\right)(1-\theta) N>0$ because from $(20), 1>\theta>0$. Second, $\left(N \eta_{c}-1\right)(N-1)>0$ since for $\operatorname{large} N, \eta_{c}>\frac{1}{N} \rightarrow 0$. Thus compared to a firm within a competitive industry, a monopolist, because of decreasing absolute risk aversion assumption, has a lower risk attitude and is therefore able to absorb more risk. In other words, it attaches a lower cost to uncertainty as compared to a competitive firm.

The second effect that may contribute toward making $\alpha_{c}>\alpha_{m}$ is given by the second term in (23), $\left\{\sigma_{c c}^{2}-\sigma_{c m}^{2}\right\}$. This term is always non-negative and it should in general take on a positive sign for the following reason. The price variance $\sigma^{2} \equiv \sigma^{2}\left(q, s^{2}\right)$ in general depends not 
only on $q$ but also $\mathrm{s}^{2}$ which is the true variance of the distribution of the random variable of Since neither the monopolist nor the competitive firm knows the true parameters of $\epsilon$, parameters such as the variance $s^{2}$ need to be estimated. For the competitive firm, its estimate of $s^{2}$, defined by ${ }^{2}{ }_{c}^{2}$ is based on information only of past prices which are independent of its own individual output levels. However, the monopolist, in its estimate of $s^{2}$ (defined by $s_{m}^{2}$ ) can exploit an added information given by the relationship between its past output levels and prices. In other words, the monopolist has an informational advantage in that its estimate $s_{m}^{2}$ is "partly explained" by its own actions (i.e., its past output levels) whereas the competitive firm's estimate $s_{c}^{2}$ is totally "unexplained" by its own past actions or output levels. Hence in general, $s_{m}^{2} \leq s_{c}^{2}$. Furthermore, given the assumption that $\partial \sigma^{2} / \partial s^{2}>0$, it follows that for the same output level $q_{c}, \sigma_{c c}^{2} \equiv \sigma_{c}^{2}\left(q_{c}, s_{c}^{2}\right) \geq \sigma^{2}\left(q_{c}, s_{m}^{2}\right) \equiv \sigma_{c m}^{2}$.

It can, of course, be argued that such informational advantage cannot persist since information can generally be acquired even by a competitive firm. This argument, however, does not nullify our conclusion that $\sigma_{c m}^{2} \leq \sigma_{c c}^{2}$ because acquiring information is costly; and at least in our example where the crucial information is the relationship between output levels and prices, the information acquisition cost of a competitive firm is at least as high as that of a monopolist.

It should be noted that our above argument is related to the general idea that centralization of activities will in general reducé informational cost. In a decentralized system of many decision makers, each faces not only exogenous uncertainty from outside the industry (e.g., exogenous random shifts in demand), but a lso uncertainty from within the industry (e.g., the output levels of other firms which in 
aggregate affect the market demand distribution). On the other hand, a single decision maker or in general, a centralized system, can avoid the latter type of uncertainty--hence reducing its overall cost of uncertainty. The third effect that affects $\alpha_{c}-\alpha_{m}>0$ lies in the term $\partial \sigma_{c m}^{2} / \partial q_{c}$ in (23). Note that $\sigma_{c m}^{2} \equiv \sigma^{2}\left(q_{c}, s_{m}^{2}\right)$ and $\sigma_{c c}^{2} \equiv \sigma^{2}\left(q_{c}, s_{c}^{2}\right)$. Abstracting from the differential estimate of variance of $e$ between the monopolist (i.e., estimate $s_{m}^{2}$ ) and the competitive firm (i.e., estimate $s_{c}^{2}$ ), there still remains a fundamental difference between them regarding their information about the random demand conditions. To a competitive firm, $\partial q_{c} / \partial q_{i}$ is by definition equal to zero so that $\partial \sigma_{c c}^{2} / \partial q_{i}=0$. This simply says that its output level is percefved to have a negligible impact on the price distribution. This is nothing but the uncertainty analogue of the certainty model in which a competitive firm's output is assumed not to affect the market price. To a monopolist, however, its output level affects not only the expected market price but also the price variance. What then is the sign of $\partial \sigma_{\mathrm{cm}}^{2} / \partial q_{c}$ ? clearly the answer depends on the functional form of the demand function and on the way the random varlable $e$ enters the function.

It is readily verified that there exists a large class of frequently used random demand functions that will guarantee $\partial \sigma_{\mathrm{cm}}^{2} / \partial q_{c}<0$ which in ? turn would contribute further toward making $\alpha_{\mathrm{c}}>\alpha_{\mathrm{m}}$. For example, consider the class of functions where the random variable enters the demand function in a multiplicative fashion: $p=p(q) \cdot g(\Theta)$ where $p^{\prime}<0$. In this case, $\partial \sigma^{2} / \partial q \equiv \partial \operatorname{var}(p) / \partial q=2 p p^{\prime} \operatorname{var}(g(\theta))<0$. Even for the more general forms such as the translog demand function: $\log p=a+b \log q+c \log \epsilon+d \log e q\left(\right.$ with $b+d<0$ to ensure $\left.p^{\prime}<0\right)$, 
we have $\partial \sigma^{2} / \partial q \equiv \partial \operatorname{var}(p) / \partial q=2(b+d) a^{2} q^{2(b+d)-1} \operatorname{var}\left[e^{(c+d)}\right]<0$ Similarly, it can be easily verified that for many other demand functions which are quadratic or convex in $e$, we also get $\partial \operatorname{var}(p) / \partial q<0$.

In summary, we have shown that in an environment of demand uncertainty, there exists at least three effects that will cause $\alpha_{c}>>\alpha_{m}$. More importantly, all these effects occur under a very general set of conditions. The first effect--the economies of scale in risk avoidance--is always operative given the assumption of decreasing absolute risk aversion. This assumption is in fact the most plausible form of restriction that can be placed on the utility function (see Arrow (1964)). The second effect--arising from the monopolist's informational superiority in the prediction of $s_{m}^{2}\left(\leq s_{c}^{2}\right)-$-is also always operative since at the minimum the absence of any predictive superiority only suggests that the true parameter $s^{2}$ of the distribution of $\epsilon$ is common to both the monopolist and the competitive firm (1.e., $s^{2}=s_{m}^{2}=s_{c}^{2}$ ). The third effect is again related to the monopolist's informational superiority in the sense that he knows his output level affects the demand distribution: e.g., the expected price and the price variance. For a large class of frequently used demand functions for which $\partial \operatorname{var}(p) / \partial q<0$ he can exploit this situation by producing more since a higher output level lowers the price variance and hence reduces the risk it needs to absorb.

Furthermore to the extent that $\alpha_{c}-\alpha_{m}>>0$ is sufficiently large as to more than offset $E[\delta](<0)$ as in $(18)$, then monopoly output will exceed that of a competitive industry, thus reversing the conventional. presumption that monopoly always incur a welfare loss relative to the competitive industry. 


\section{v. Conclusions and Implications}

One of the most accepted results in economic theory is that, given the same cost conditions and in a certainty environment, a monopolist will always produce less than a competitive industry--with the consequence that monopoly always causes a welfare $108 s$ to society. In an environment of uncertainty, another standard result (see Sandmo (1971), Leland (1972)) exists which suggests that increasing uncertainty would lead a firm (whether a monopolist or competitive firm) to reduce its output because of risk aversion or avoidance. Furthermore, there is a presumption, as exemplified by the Galbraith-Caves hypothesis (Galbraith (1967), Caves (1970)), that a firm with greater market power (e.g., monopolist) would exhibit greater risk avoidance. This of course would lead one to conclude that increasing uncertainty would cause a monopolist to reduce its output much more than a competitive firm; thus accentuating the welfare 1088 argument associated with monopoly.

This paper has shown that while it is true that increasing uncertainty reduces the monopolist's and the competitive industry's output (this result being assured by $\alpha_{\mathrm{m}}>0, \alpha_{\mathrm{c}}>0$ ), it is however not true in general that the monopolist would react to increasing uncertainty by shrinking its output level by more than a competitive industry. On the contrary, it was shown that under a very general and plausible set of conditions, a monopolist will exhibit a smaller risk avoidance as compared to a competitive firm--i.e., $\alpha_{c}>\alpha_{m}$--with the consequence that increasing uncertainty would lead a monopolist to reduce its output level by less than a competitive industry. This result implies that in an environment of uncertainty, the welfare loss associated with monopoly is in fact reduced relato competition. Furthermore, it is not inconceivable that the welfare loss 
associated with monopoly might turn out to be smaller than the one associated with competition. Such would be the case if $\alpha_{c}-\alpha_{m} \gg 0$ is sufficiently large to offset the negative $E[\delta]$ monopoly effect as in (18).

Finally, the results of our model have a further interesting implication regarding the measurement of monopoly power. Rewrite the monopolist's first order condition (16) as

$$
\vec{p}_{m}(1-\xi)=M_{m}+\alpha_{m}
$$

where $\vec{p}_{m} \equiv E\left[p\left(q_{m}, Q\right)\right]$ is the expected price, $\xi \equiv-E[\delta] / \bar{p}_{m}$ is the absolute value of the inverse expected demand elasticity; $M_{m} \equiv C_{C}^{\prime}\left(q_{m}\right)$ is the marginal cost; and $\alpha_{m} \equiv \alpha_{m}\left(q_{m}\right)$ is the monopolist's marginal risk premium. The equilibrium for the competitive industry, given by (17) can be rewritten as

$$
\overline{\mathrm{p}}_{\mathrm{c}}=\mathrm{MC}_{\mathrm{c}}+\alpha_{\mathrm{c}}
$$

where

$$
\overline{\mathrm{p}}_{\mathrm{c}}=\mathrm{E}\left[\mathrm{p}\left(\mathrm{q}_{i}, \epsilon\right)\right] ; \alpha_{\mathrm{c}} \equiv \alpha_{\mathrm{c}}\left(q_{\mathrm{c}}\right) ; \text { and } \mathrm{MC}_{\mathrm{c}} \equiv \mathrm{MC}_{\mathrm{c}}\left(\mathrm{q}_{\mathrm{c}}\right) \text {. }
$$

In the case of no uncertainty, i.e., $\alpha_{c}=\alpha_{m}=0$, the standard Lerner measure ${ }^{6}$

$$
\mathrm{L}_{\mathrm{m}}^{\mathrm{n}} \equiv\left(\overline{\mathrm{p}}_{\mathrm{m}}-\mathrm{MC}_{\mathrm{m}}\right) / \overline{\mathrm{p}}_{\mathrm{m}}=\xi
$$

(where $0<\xi<1$ ). This says the degree of deviation from marginal cost pricing--and hence the efficiency loss--is due solely to the standard monopoly element $\xi$. This is an appropriate measure of inefficiency since for the competitive industry, the Lerner measure (when $\alpha_{c}=0$ )

$$
L_{c}^{n} \equiv\left(\bar{p}_{c}-M_{c}\right) / \bar{p}_{c}=0
$$

Identically reduces to zero.

In the case of uncertainty, however, both the competitive industry and the monopoly deviate from marginal cost pricing. For instance, the index of 
such a deviation defined for the monopoly case can be inferred from (24) as

$$
\mathrm{L}_{\mathrm{m}}^{\mathrm{u}} \equiv\left(\overline{\mathrm{p}}_{\mathrm{m}}-\mathrm{MC}_{\mathrm{m}}\right) / \overline{\mathrm{p}}_{\mathrm{m}}=\xi+\alpha_{\mathrm{m}} / \overline{\mathrm{p}}_{\mathrm{m}}>0
$$

The deviation here is not only due to the traditional monopoly argument $\xi$ but also due to the risk avoidance term $\alpha_{\mathrm{m}} / \overline{\mathrm{p}}_{\mathrm{m}}$. In the case of competition, the deviation measure can be inferred from (25) as

$$
\mathrm{L}_{\mathrm{c}}^{\mathrm{u}} \equiv\left(\overline{\mathrm{p}}_{\mathrm{c}}-\mathrm{MC}_{\mathrm{c}}\right) / \overline{\mathrm{p}}_{\mathrm{c}}=\alpha_{\mathrm{c}} / \overline{\mathrm{p}}_{\mathrm{c}}>0
$$

which does not reduce to zero.

This deviation from marginal cost pricing arises with both forms of market structure. This suggests that one should be careful in the interpretation of such measure. In a certainty model, Lerner's measure of monopoly power $\xi$ precisely measures the degree of inefficiency. In the case of uncertainty, our results suggest that the deviation due to competition $L_{c}^{u}$ could plausibly exceed the deviation due to monopoly, $L_{m}^{u}$. In a world where the first-best marginal cost pricing rule is not attainable, the relevant comparison is between the alternative possible second-best outcomes, 1.e., $L_{c}^{u}-L_{m}^{u}$ which can turn out to be either positive or negative. 


\section{Foot notes}

${ }^{1}$ Although we have restricted ourselves to the case of demand uncertainty, a similar analysis can be applied to cost uncertainty.

2.See Galbraith (1967) and Caves (1970). See also Edwards and Heggestad (1973) for a formalization and the test of the Galbraith-Caves hypothesis. ${ }^{3} \mathrm{~A}$ similar result is derived in Appelbaum and Lim (1980) in the context of a general monopolistic competition model.

${ }^{4}$ See Pratt (1964). See also Samuelson (1970) for a defence of local approximations when the probability distribution is compact and concentrated.

5

It. can be shown that relaxing the restriction $R^{\prime \prime}=0$, will only strengthen our results. For example, if we take $u^{\prime \prime \prime \prime}=0$, it follows that $R^{\prime \prime}<0$, which will further lead to a reduction in the monopolist's risk avoidance $\alpha_{\mathrm{m}}$ relative to $\alpha_{\mathrm{c}}$.
6 See Lerner $(1934)$. 


\section{References}

Appelbaum, E., and Lim, C. (1980), "Risk and Market Structure," paper presented to the Fourth World Congress of the Econometric Society, Aix-en-Provence, France, September, 1980.

Arrow, K. J. (1965), Aspects of the Theory of Risk Bearing, Helsink1; Yrjo Johns8onin Saatio".

Caves, R. E. (1970), "Uncertainty, Market Structure and Performance: Galbraith as Conventional Wisdom," in J. W. Markham, and G. F. Papanek, eds., Industrial Organization and Economic Development, Boston: Houghton Miffiln Co., 283-302.

Edwards, F. R., and Heggestad, A. A. (1973), "Uncertainty, Market Structure and Performance in Banking," Quarterly Journal of Economics, LXXVII, 455-473.

Galbralth, J. K. (1967), The New Industrial State, Boston: Houghton Mifflin Co. Leland, M. (1972), "Theory of the Firm Facing Uncertain Demand," American Economic Review, 62, 278-291.

Lerner, A. P. (1934), "The Concept of Monopoly and the Measurement of Monopoly Power," Review of Economic Studies, 1, 157-175.

Pratt, J. W. (1964), "Risk Aversion in the Small and in the Large," Econometrica, 32, $122-136$.

Samuelson, P. A. (1970), "The Fundamental Approximation Theorem of Portfollo Analysis in Terms of Means, Variances, and Higher Moments," Review of Economic Studies, 37, 537-542.

Sandmo, A. (1971), "On the Theory of the Competitive Firm Under Price Uncertainty," American Economic Review, 61, 65-73. 